which had witnessed the bestowing of honorary degrees on Lafayette and Ephraim McDowell. On April 26, Dr. Sigerist spoke on "Science and Technology in the Renaissance", and to the afternoon's seminar on "Some Biological Problems of the Renaissance" Dr. Larkey contributed an account of the anatomical text-books of the period, while Dr. Temkin discussed the anti-Aristotelian movement. On April 27, Dr. Temkin, lecturing on "The Physician in the Renaissance", attributed the esteem in which he was held not to his efficiency (in contemporary satires he is more freely attacked than the surgeon), but rather to the academic and financial difficulties attending the acquisition of the M.D. in the sixteenth century. Bearing in mind that the average lifetime of a man in those days was not more than fifty years, at the end of his training the young doctor had already spent more than half his life in study. The medieval physician was restricted in his interests, all scientific knowledge being centred in the philosophers and the theologians. With the Renaissance, the physician began to enter the field of mathematics, mineralogy, chemistry, zoology, and literature. The afternoon's seminar dealt with "Diseases prevailing in the Renaissance and their Interpretation". On
April 28, Dr. Larkey spoke on "Hygiene and Public Health in the Renaissance", the subject of the afternoon's discussion being "Medical Literature in the Vernacular : English, German, French, Italian". The closing address of the course was delivered by Dr. Alan M. Chesney, dean of the Medical School, who dealt with the early history of the Johns Hopkins Hospital, the fiftieth birthday of which is commemorated this month.

The intellectual fare of the Graduate Week was temptingly seasoned with tea and cocktail parties, dinners and visits to shrines of interest, such as the Tudor and Stuart Club of Johns Hopkins University, with which the name of Revere Osler, Sir William's only son, is inseparably linked.

The following exhibits had been arranged: Leonardo da Vinci ; medical books from the Renaissance presses; and recently published literature in medical history.

At the banquet on April 28, Dr. John Rathbone Oliver spoke on "The Oxford of Anthony Wood", and a presentation was made to Dr. Sigerist and to the very efficient and charming machine behind his brain--his secretarial staff.

WALTER BETT.

\title{
Soil Mechanics
}

$\mathrm{P}$ ROF. KARL VON TERZAGHI delivered the forty-fifth James Forrest Lecture at the Institution of Civil Engineers on May 2, taking as his subject "Soil Mechanies: a New Chapter in Engineering Science".

At the opening of his address, Dr. von Terzaghi contrasted the empirical methods which were in general use until about twenty-five years ago with the much greater reliability which is now obtainable by allowing for the effects of soil movements and pressures. So unsatisfactory to progressive engineers had the old procedure become of ascertaining the bearing capacity of subsoil that concerted action was taken to study the properties and behaviour of soil and to place these on a sound basis in accordance with the laws of mechanics. The new study was designated 'soil mechanies', a name which in 1936 received confirmation when the first International Conference on Soil Mechanics and Foundation Engineering was held at Harvard University in Cambridge, Massachusetts.

Dealing with the first section of his subject, "The Pressure of Earth on Lateral Supports", Dr. von Terzaghi showed that Coulomb's theory, which is the more reliable of the two in use and dates from 1773 , was based on several untenable assumptions. The modifications made in the formulæ as now used have arisen from the discovery that the intensity and distribution of earth pressure depend on many more factors than were realized by earlier workers. Dr. von Terzaghi indicated the nature of, and justification for, these modifications.

Passing to the closely related problem of earth pressures involved in the stability of slopes, Dr. Terzaghi showed that the old method was to prescribe that slopes of fills and cuts should be established at angles somewhat smaller than the appropriate angles of repose. Mention was made of what is known as the Swedish method of determining the degree of stability of a slope, which is based on the empirical fact that the profile of the surface of sliding always approaches the form of a circular arc. For masses of earth having little cohesion and subjected to seepage forces, as in the case of an embankment for water storage, the formulæ adduced in recent studies were shown to give satisfactory results. In the case of clays, however, the determination of the shearing resistance is far more difficult and the position at present is still highly controversial.

A submerged body of soil with little cohesion and in a loose state is liable on the least disturbance to behave as a liquid and to flow on a horizontal surface, a phenomenon which is known as 'flow-slide'. Here the condition was shown to be that the material should be loose enough to be capable of reducing to a denser state as a result of the applied deformation. Flow-slide was thus shown to be associated with porosity, and no flow failure can occur unless the volume at this occurrence is less than the initial volume. The necessity, therefore, of specifying that the porosity of water-retaining embankments should be well below the critical value was thus made clear.

The compaction of embankments is an effective means of limiting the amount of settlement, as in the case of fills for road making, and R. R. Proctor has demonstrated that the degree of compaction produced by a given method depends on the moisture content, being greatest for a certain medium watercontent, determinable by experiment. These observations have led to fill-construction methods in which moisture-content controls are introduced. In Germany, the compaction of sandy soil by vibration has been brought to a high state of perfection, and it has been found that the greatest compacting effect is 
produced when the frequency of the vibrator is equal to the specific vibration of the soil. The same process is also used for comparing the degree of compaction of fills before and after completion.

Dr. von Terzaghi then dealt with the failure of dams due to piping, a subject which is nearly allied, from the point of view of its mechanics, to the stability of slopes subjected to seepage forces. Bligh's empirical rule was faulty in that it was based on the tacit assumption that the critical percolation factor depends only on the grain size of the subsoil. By model dams so constructed that, by Bligh's rule, the critical head should have been the same for all, it was shown by the highly divergent results that the assumption is greatly in error. Dr. von Terzaghi explained how he came to the conclusion that piping can be eliminated by the provision of an inverted filter between the body of the dam and the foundation, and he described such a filter which he has designed for incorporation in a rock-fill dam in Algiers.

The time factor in relation to earth pressures and movements was next discussed. Using a cylinder filled with water and having a perforated piston supported by springs as an illustration, Dr. von Terzaghi pointed to the fact that, when a constant load is applied, the piston can only descend as the water percolates through the interstices in the piston. At first the water pressure supports the load, but it falls off as the descending piston compresses the spring. A similar process occurs in clay when loaded, and the mechanics of it can be expressed, in terms of time, by a partial differential equation of the second degree. This is known as the fundamental equation of the processes of consolidation. The case was quoted of a power-house where, for a supply of water, a well was driven through the clay to water-bearing gravel below. As a result, the time-rate of settlement of the power-house increased alarmingly, and within a few months the corner nearest the well had subsided more than a foot. When the well was closed, the settlement practically ceased. Dr. von Terzaghi pointed to other instances in which the operation of the theory of consolidation is exemplified, and explained that settlements of this nature can now be computed with reasonable accuracy.

\section{University Events}

Cambridge.-Dr. J. D. Cockcroft, lecturer in physics in the University and fellow of St. John's College, has been elected Jacksonian professor of natural philosophy as from October l (see also p. 846).

LoNDon.-The following representatives have been elected by Convocation to the Senate : Medicine, Sir Ernest Graham-Little, M.P. ; Science, Prof. G. B. Jeffery, Prof. Major Greenwood; Engineering, Sir Charles Bressey.

A Keddey Fletcher-Warr studentship, of the value of $£ 300$ a year for three years, has been awarded to Dr. Vernon E. Cosslett (Birkbeck College), for research on the application of electron optics to the design of $\mathrm{X}$-ray tubes and to the measurement of X-ray diffraction patterns.

SfefrimLd.-Alfred Wright, at present research assistant in mining, has been appointed lecturer in mining ; J. W. Watson has resigned from his post of assistant lecturer in geography.

\section{Science News a Century Ago}

Wells in the London Clay in Essex

IN a paper read to the Geological Society on May 22, 1839, Dr. Mitchell dealt with "The Wells in the Gravel and London Clay in Essex". The greater part of Essex, he said, consists of London Clay. The greatest thickness of the clay is not known, but it probably exceeds $400 \mathrm{ft}$. Extensive districts are covered by gravel, sand and detritus. In the districts composed of London Clay, no land springs occur and the wells generally penetrate to the bed of sand between the Clay and the challk. The Clay is of various colours, the lower beds being sometimes red, but it is sometimes blue at the bottom. In the districts where it is thickest, it is often interstratified with two or three beds of sand, but near the site of Fairlop Fair, it was found to consist of $398 \mathrm{ft}$. of solid clay. Dr. Mitchell gave a list of nineteen wells, selected from a very large number, the deopest being in Foulness Island, $460 \mathrm{ft}$. Artesian wells have been productive of the greatest benefit in Essex.

\section{Photography with the Aid of Incandescent Coke}

IN the Athenceum of May 25, 1839, it was said under the heading "Photogenic Drawing", that "Mr. Robert Mallet has communicated to the Royal Irish Academy a notice of the discovery of the property of the light emitted by incandescent coke to blacken photogenic paper; and proposed it as a substitute for solar light, or that from the oxyhydrogen blow pipe with lime. One of the most important applications of the photogenic process, as yet suggested, is its adaptation to the self-registering of long-continued instrumental observations. . . . Few artificial lights emit enough of the chemical rays to act with certainty on the prepared paper; while those which are known to act well, as the oxyhydrogen light, are expensive and difficult to manage. A considerable time since, the author discovered that the light emitted by incandescent coke at the 'Twyer' (or aperture by which the blast is admitted) of a cupola or furnace for melting cast iron, contained the chemical rays in abundance; and on lately trying the effect of this light on the prepared paper, he found it was intensely blackened in about forty-five seconds.

Robert Mallet (1810-80), engineer and physicist, was a graduate of Trinity College, Dublin, and was a partner with his father. Among his works was the Fastnet Lighthouse. $\mathrm{He}$ was well known for his study of volcanoes and earthquakes. He was elected a fellow of the Royal Society in 1834.

\section{A Criticism of Davy's Safety Lamps}

'THE Mechanics' Magazine of May 25, 1839, published a report of a lecture by Faraday at the Royal Institution on May 10, on "Some General Remarks on Flame". Faraday had referred to Davy's safety lamps, and in its comments on the lecture, the Mechanics' Magazine said : "We have no disposition whatever to detract from the merit or brilliancy of Sir H. Davy's discovery as a scientific fact, but the lamp is a poor fragile thing. . . . Thus instead of protecting the light in a strong lantern he (Davy) contented himself with merely placing around it a flimsy tissue of wire, which besides numerous other objections, is, by its gloomy effect, ever tempting the miner to remove it, or to use a better but more dangerous light. 